\section{Evaluation of Ornamental Tropical Plants for Resistance to White Mold Caused by Sclerotinia sclerotiorum}

\author{
Michelle A. Grabowski ${ }^{1}$ and Dean K. Malvick \\ Department of Plant Pathology, University of Minnesota, 1991 Upper Buford \\ Circle, 495 Borlaug Hall, Saint Paul, MN 55108
}

Additional index words. Caladium $\times$ hortulanum, Caladium, Canna $\times$ generalis, Canna,
Colocasia esculenta, elephant ear

\begin{abstract}
Sclerotinia sclerotiorum (Lib.) de Bary is a fungal pathogen that causes stem rot, crown rot, wilt, and death of many common annual flowering plants. Infested flower beds often suffer significant plant loss each year, and the identification of disease resistant plants would be a useful management tool. Caladium (Caladium $\times$ hortulanum Birdsey), canna (Canna $\times$ generalis L.H. Bailey), and elephant ear [Colocasia esculenta (L.) Schott] were evaluated for potential resistance to $S$. sclerotiorum. Plants grown in field conditions in Minnesota in 2012 and 2013 were inoculated through the application of sorghum grains colonized by $S$. sclerotiorum. The number of plants infected and percent of canopy dieback were recorded weekly for 3 months. The susceptibility of leaves, flowers, and below ground storage organs was also examined through direct inoculation of plant tissue with a mycelial plug of the pathogen in controlled environmental conditions favorable for disease development. Symptoms and progression of the infection were recorded after 24 days. Symptoms of infection on all three species were similar in field and controlled environments. Caladium plants were susceptible to $S$. sclerotiorum. Petioles, leaves, and corms developed a watery soft rot. Elephant ear was highly resistant to infection. Sclerotinia sclerotiorum infected only wounded or senescent tissue and did not result in significant symptoms under any conditions. Canna had partial resistance to the pathogen. Although canna petals were readily infected, infection of petioles was restricted to small necrotic lesions. Neither infection progressed to the main stem or resulted in plant death. This study indicates that canna and elephant ear have resistance to $S$. sclerotiorum and could be used in an integrated disease management program for infested landscape beds.
\end{abstract}

White mold, caused by the necrotrophic fungal pathogen Sclerotinia sclerotiorum, causes stem rot, crown rot, wilt, and death of many common annual bedding plants, including zinnia, petunia, verbena, snap dragon, and salvia (Boland and Hall, 1994; Farr and Rossman, 2017; Grabowski and Malvick, 2015). Infested flower beds often suffer significant plant loss each year in part due to the ability of the pathogen to survive for at least 8 years in soil (Bolton et al., 2006). Infection occurs in cool moist conditions and plant death from white mold occurs in mid to late summer (Abawi and Grogan, 1979; Bolton et al., 2006). At this stage of the growing season, replacement plants for summer flowering annuals are typically no longer available. Garden managers are left with unsightly patches of dead plants or bare soil.

Identifying ornamental plants with resistance to white mold would allow growers to avoid disease problems in beds known to be

\footnotetext{
Received for publication 26 May 2017. Accepted for publication 27 July 2017.

Funding for this project was provided by the Minnesota Turf and Grounds Foundation.

This article is a portion of a thesis by Michelle A. Grabowski in fulfilling degree requirements for the University of Minnesota.

${ }^{1}$ Corresponding author. E-mail: magrabow@umn. edu.
}

infested with $S$. sclerotiorum. Over 400 plant species from more than 75 families are known to be susceptible to $S$. sclerotiorum (Boland and Hall, 1994). Gleason et al. (2009) list over 30 genera of herbaceous perennials and Daughtrey et al. (1995) list 10 common flowering potted plants that are susceptible to $S$. sclerotiorum. New susceptible host plants are regularly identified (Chang et al., 1997; Garibaldi et al., 2008a, 2008b, 2008c, 2001; Grabowski and Malvick, 2015; Gulya et al., 2006; Strauss and Dillard, 2009). Grabowski and Malvick (2015) tested four genera of annual bedding plants with no reported susceptibility to white mold for potential resistance to $S$. sclerotiorum. Although moderate resistance was found, plants from all four genera became infected by $S$. sclerotiorum to some degree. To identify plants with reliable resistance to white mold, new taxa of ornamental plants need to be evaluated for resistance.

Ornamental tropical plants are often grown in annual flower beds to add color and texture. Canna, caladium, and elephant ear have a long history of cultivation. Canna originates from South America and was first introduced to European gardeners as a foliage plant in 1595 (Khoshoo and Mukherjee, 1970; Prince, 2011). Caladium originates from tropical regions of Central and South America (Germplasm Resources Information
Network, 2017). Breeding of hybrid garden caladium has occurred for over 150 years (Deng et al., 2007). Elephant ear, also known as taro, originates from Southeast Asia and is believed to be one of the oldest domesticated crops (Quero-Garcia et al., 2010). Plants from these genera are readily available to landscape managers in a variety of colors to meet designers' needs. Cultivation and care of these plants in gardens is well described (Iversen, 1999), allowing for easy adoption of plants should they prove resistant to white mold.

Perhaps because they are of tropical origin, plants in these genera have few pest problems in temperate climates (Horst, 2001; Iversen, 1999) and no recorded history of infection by $S$. sclerotiorum (Boland and Hall, 1994; Farr and Rossman, 2017). In addition, all are monocots. Although some monocots are listed as hosts to S. sclerotiorum, economic damage due to this pathogen primarily occurs in dicotyledonous plants (Boland and Hall, 1994; Bolton et al., 2006; Farr and Rossman, 2017).

Although canna, caladium, and elephant ear are grown as annuals in temperate climates, each produces a belowground storage organ (rhizome, tuber, corm) that can be dug up at the end of the season, stored for the winter, and planted the following season. Belowground storage organs can be used to propagate these plants as well (Iversen, 1999). In addition to evaluating resistance to infection of aboveground plant parts, it is important to determine the susceptibility of corms, tubers, and rhizomes. White mold is known to spread in storage on crops such as carrot (Koike, 2007). If corms, tubers, and rhizomes of tropical ornamentals were infected, similar spread in storage would be likely.

The objective of this study was to evaluate three commonly grown tropical ornamentals, canna, caladium, and elephant ear for potential resistance to $S$. sclerotiorum.

\section{Materials and Methods}

Plant materials for field studies. All plants were grown in a composted bark potting mix (Sungro Horticulture, Agawam, MA) with one plant per pot in a greenhouse with $12 \mathrm{~h}$ light at $25{ }^{\circ} \mathrm{C}$ and $12 \mathrm{~h}$ darkness at $20{ }^{\circ} \mathrm{C}$ before transplanting into field plots. Cultivars that are readily available to garden managers were chosen for the experiment. Corms of 'Ruffles' elephant ear, purchased from a local garden center, were grown in $25.4 \mathrm{~cm}$ round pots for 10 weeks. Tubers of 'White Queen' caladium that were 3.8 to $6.4 \mathrm{~cm}$ in diameter (Classic Caladiums, Avon Parks, FL) were grown for 5 weeks in $10.2 \mathrm{~cm}$ pots. Seeds of 'Tropical White' canna (Stokes Seeds Inc., Buffalo, NY) were planted 12 weeks before the start of the experiment in $10.2 \mathrm{~cm}$ pots. Zinnia elegans xangusifolia 'Profusion White' seedlings, included as a known susceptible control, were purchased from a local garden center and transplanted into $10.2 \mathrm{~cm}$ pots two weeks before the start of the 
experiment. All plants had 2-5 fully expanded leaves at the time of transplant.

Inoculum preparation. Three isolates of S. sclerotiorum were used in the experiment: ORN010, isolated from a petunia plant in Chaska, MN; FC002, isolated from a soybean plant in Renville County, MN; and VEG001, isolated from green bean in Spring Valley, WI. Sclerotia of each isolate were produced and stored as described in Grabowski and Malvick (2015).

Field studies of disease susceptibility. All plant entries were transplanted on June 5 in a randomized complete block design with four replicated blocks on the Minnesota Agricultural Experiment Station, St. Paul campus. The experiment was conducted twice, in 2012 and 2013. Each experimental unit contained four plants of the same cultivar in two rows of two plants. Plants were spaced to create canopy closure at the same time despite differences in plant size. Zinnia and caladium plants were spaced $25.4 \mathrm{~cm}$ apart within plots. Canna plants were planted 40.6 and $35.6 \mathrm{~cm}$ apart in 2012 and 2013, respectively, and elephant ear plants were planted 50.8 and $35.6 \mathrm{~cm}$ apart in 2012 and in 2013, respectively, due to differences in transplant size. Plants were watered once a day for $20 \mathrm{~min}$ with an oscillating sprinkler before inoculation. Osmocote 14-14-14 was applied 2 weeks after planting at $340 \mathrm{~kg} \cdot \mathrm{ha}^{-1}$ to all plots.

Plots were inoculated with a mixture of equal quantities of sorghum seed colonized by three isolates of $S$. sclerotiorum, which was prepared as described by Grabowski and Malvick (2015). The inoculum mixture was spread evenly over the plant canopy at 86.5 L.ha ${ }^{-1}$ when the trial plants had grown together to achieve canopy closure and again one week later. Canopy closure was reached in the fourth week of July in both years. Irrigation was applied with an oscillating sprinkler for 5 min immediately after inoculation and subsequently applied three times daily for $10 \mathrm{~min}$ for the remainder of the experiment. Following the inoculations, the daily maximum temperature ranged from 24 to $33{ }^{\circ} \mathrm{C}$ in 2012 and 24 to $30{ }^{\circ} \mathrm{C}$ in 2013 and the daily minimum temperature ranged from 14 to $24{ }^{\circ} \mathrm{C}$ in 2012 and 14 to $18^{\circ} \mathrm{C}$ in 2013 .

Disease incidence and severity were recorded every $7 \mathrm{~d}$ after inoculation (DAI) until mid-September. Disease incidence was recorded as the number of plants per plot that were visibly infected with $S$. sclerotiorum based on signs and symptoms. Any plant with questionable symptoms was surface disinfested with an aqueous solution of $0.525 \%$ sodium hypochlorite and plated on halfstrength potato dextrose agar medium $(1 / 2 x$ PDA, Becton, Dickinson and Company, Franklin Lakes, NJ) at the end of the experiment to confirm infection by S. sclerotiorum. Disease severity was recorded as percent canopy missing or dead due to infection of plants within the bed. The area under disease progress curve (AUDPC) was calculated to compare disease progress over time (Madden et al., 2007).
Studies of disease susceptibility in con\#9;trolled environments. Plants were grown for inoculation as described previously. 'Fannie Munson' caladium and 'Tropical Yellow' canna were added to the trial. To produce small plants that were suitable for use in growth chamber trials, corms of 'Ruffles' elephant ear were propagated from plants maintained in the greenhouse as described previously during March through September one year before the experiment. In October, stems were cut off at the soil line, and pots were allowed to dry for 2 weeks. The corm and potting soil from all pots were placed in a plastic bag and stored at $10{ }^{\circ} \mathrm{C}$. Before the experiment, potting soil was gently removed from the corms; corm offsets were broken off the central bulb by hand and sorted by size. All offsets were carefully inspected; any offsets showing signs of rot or injury were discarded. Corm offsets that were 2.5 to $5 \mathrm{~cm}$ in diameter were planted 10 weeks before the start of the experiment in $12.7 \mathrm{~cm}$ square pots. All plants were maintained in a greenhouse as described previously and had 2-5 fully expanded leaves before inoculation. Sclerotia from each of the three isolates described previously were placed individually on $1 / 2 x$ PDA five days before the experiment and incubated at $22^{\circ} \mathrm{C}$ to promote mycelial growth.

Inoculation of foliage. The experiment was a completely random design with two factors, isolate and plant entry, replicated three times with one plant per replication. An $8 \mathrm{~mm}$ square of agar containing the leading edge from one of the three isolates of $S$. sclerotiorum culture was placed between the plant stem and the petiole of the oldest leaf of the plant that was still green and healthy. Mock inoculated control plants were prepared for inoculation in a similar fashion but received only sterile $1 / 2 x$ PDA. All plants were incubated in a mist chamber with a $12 \mathrm{~h}$ photoperiod at $22{ }^{\circ} \mathrm{C}$ and misted $10 \mathrm{~min}$ per hour for 2 DAI. Then, plants were moved to a growth chamber (Environmental Growth Chambers, Chagrin Falls, OH) set to $18{ }^{\circ} \mathrm{C}$ for $14 \mathrm{~h}$ of light and $16{ }^{\circ} \mathrm{C}$ for $10 \mathrm{~h}$ of darkness. Plants were hand-watered as needed with water directed to the soil. No significant differences in disease severity were observed on the plants inoculated with the different isolates of $S$. sclerotiorum and no interactions between isolate and plant entries were detected (data not shown). Data from all three isolates were combined for analysis of foliar infection data.

Disease severity was assessed 24 DAI as the percent of leaves wilted or killed per plant. Plants were taken out of the pots and soil was carefully removed from the surface of the corm, tuber, or rhizome. Corms, tubers, and rhizomes were bisected vertically with a sterile knife, and the depth of rot was measured from the point of leaf attachment downward toward the roots. A section of plant tissue was cut from the leading edge of the infection, surface disinfested with an aqueous solution of $0.525 \%$ sodium hypochlorite, and plated on 1/2x PDA. All plates were examined for the presence of $S$. sclerotiorum after $14 \mathrm{~d}$ of incubation at $22{ }^{\circ} \mathrm{C}$. The experiment was conducted twice.

Inoculation of elephant ear petioles. Natural senescence of the outermost leaf in elephant ear plants confounded results in the foliar inoculation study. To determine if $S$. sclerotiorum can infect nonsenescent petioles of 'Ruffles' elephant ear, an $8 \mathrm{~mm}$ square of $1 / 2 x$ PDA containing the leading edge of a culture of isolate ORN010 was placed midway between the base of the petiole and the base of the leaf. Parafilm ${ }^{\circledR}$ (Bemis Company, Inc., Oshkosh, WI) was wrapped around the inoculum and petiole to secure it to the plant. Each plant was inoculated on a newly expanded inner leaf, and the outermost, oldest leaf in the whorl. Mock inoculated controls received a sterile $8 \mathrm{~mm}$ square of $1 / 2 x$ PDA. The experiment was a completely random design with three replications. Plants were incubated as described previously and moved to a growth chamber (Environmental Growth Chambers, Chagrin Falls, $\mathrm{OH}$ ) with a $12 \mathrm{~h}$ photoperiod set to $13{ }^{\circ} \mathrm{C}$ to determine if resistance of the tropical plants persisted at the low end of the pathogen's temperature range for infection (Bolton et al., 2006), which commonly occurs during the growing season in northern states. Symptoms were recorded 28 DAI. All inoculated petioles were surface disinfested with an aqueous solution of $0.525 \%$ sodium hypochlorite, and five $1 \mathrm{~cm}$ cross sections were placed on $1 / 2 x$ PDA and examined for the presence of $S$. sclerotiorum after 14-d incubation at $22{ }^{\circ} \mathrm{C}$. The experiment was conducted twice.

To determine if wounding played a role in infection of elephant ear petioles, the inoculation was repeated as described previously for newly expanded leaves, with the modification of a shallow $1 \mathrm{~cm}$ wide wound being created on the petiole with a sterile razor blade at the inoculation site before inoculation. The wounding experiment was conducted twice.

Inoculation of canna flowers. Of the three genera, canna is the only plant that will flower regularly in northern gardens. As a result, it was important to determine if $S$. sclerotiorum could infect canna through the inflorescence. Flowers of 'Tropical White' and 'Tropical Yellow' canna were tested in a completely random design with three replications and one plant per replication. An $8 \mathrm{~mm}$ square of $1 / 2 x$ PDA containing the leading edge from a culture of isolate ORN010 was placed at the center of a newly opened flower of an inflorescence with $60 \%$ to $80 \%$ open blossoms. Mock inoculated controls received sterile 1/2x PDA. Plants were moved to a growth chamber set to $13{ }^{\circ} \mathrm{C}$ with a $12 \mathrm{~h}$ photoperiod and incubated as described previously. Disease severity was rated as the number of flowers infected at 6 and 19 DAI, and as the lesion length on the flower stalks 28 DAI. The trial was conducted twice.

Susceptibility of below ground storage organs in controlled environment. Rhizomes of 'Tropical White' canna were produced by 
growing plants from seed for 20 weeks in greenhouse conditions as described previously. Corms of 'Ruffles' elephant ear were produced through production of offsets as described previously. Tubers of 'White Queen' caladium were purchased from a commercial caladium grower (Classic Caladiums, Avon Parks, FL). Tap roots of food grade carrots, Daucus carota subsp. sativus (Hoffm.) Schübl. \& G. Martens, were included as a susceptible control.

All storage organs were wounded by creating a shallow $1 \mathrm{~cm}$ wide wedge with a sterile razor blade. A $1 \mathrm{~cm}$ square of $1 / 2 x$ PDA containing the leading edge from a $S$. sclerotiorum culture, isolate ORN010, was placed directly on the wound. Mock inoculated controls received the same treatment with a sterile square of $1 / 2 x$ PDA. Following inoculation, the storage organs were placed in a plastic bag, misted with distilled water, and the bags were kept sealed in a growth chamber set to $18^{\circ} \mathrm{C}$ for $14 \mathrm{~h}$ of light and $16^{\circ} \mathrm{C}$ for $10 \mathrm{~h}$ of darkness to optimize conditions for fungal growth and infection. At 10 DAI, samples were cut in half lengthwise and the extent of discolored and decomposing tissue was recorded based on the length of area that was symptomatic relative to the total length. A $1 \mathrm{~cm}$ square sample from the leading edge of the infection was removed, surface disinfested with an aqueous solution of $0.525 \%$ sodium hypochlorite, and plated on $1 / 2 x$ PDA. Samples were incubated for $14 \mathrm{~d}$ at $22{ }^{\circ} \mathrm{C}$ and then examined for the presence of $S$. sclerotiorum. The experiment was a completely random design with four replications and one plant per replication. The trial was conducted twice.

Statistical analysis. Data from controlled environment experiments, direct inoculation of storage organs, and field trials were combined after Hartley's $F_{\max }$ test demonstrated homogenous variance between repeated trials. Data from controlled environment experiments were analyzed as a factorial design using JMP software (SAS Institute, Inc., Cary, NC). Tukey's honestly significant difference was used to separate means. Data from direct inoculation of storage organs and field trials were not normal and could not be corrected by standard data transformations; therefore, nonparametric methods were used to analyze the data. Friedman's test was used to calculate a $\chi^{2}$ for the model and a $P$ value for treatments. Treatments with a $P$ value $\leq 0.05$ were compared using Wilcoxon's rank testing to determine differences between treatments.

\section{Results}

\section{Studies under field conditions}

Disease incidence was $100 \%$ at 7 DAI for the susceptible control 'Profusion White' zinnia (Fig. 1). Disease severity (percent canopy killed) in zinnia plots increased in a monomolecular curve until $98 \%$ of the plant canopy was killed at 49 DAI (Fig. 2). Average incidence for canna and caladium was $<60 \%$ throughout the duration of the trials. Incidence

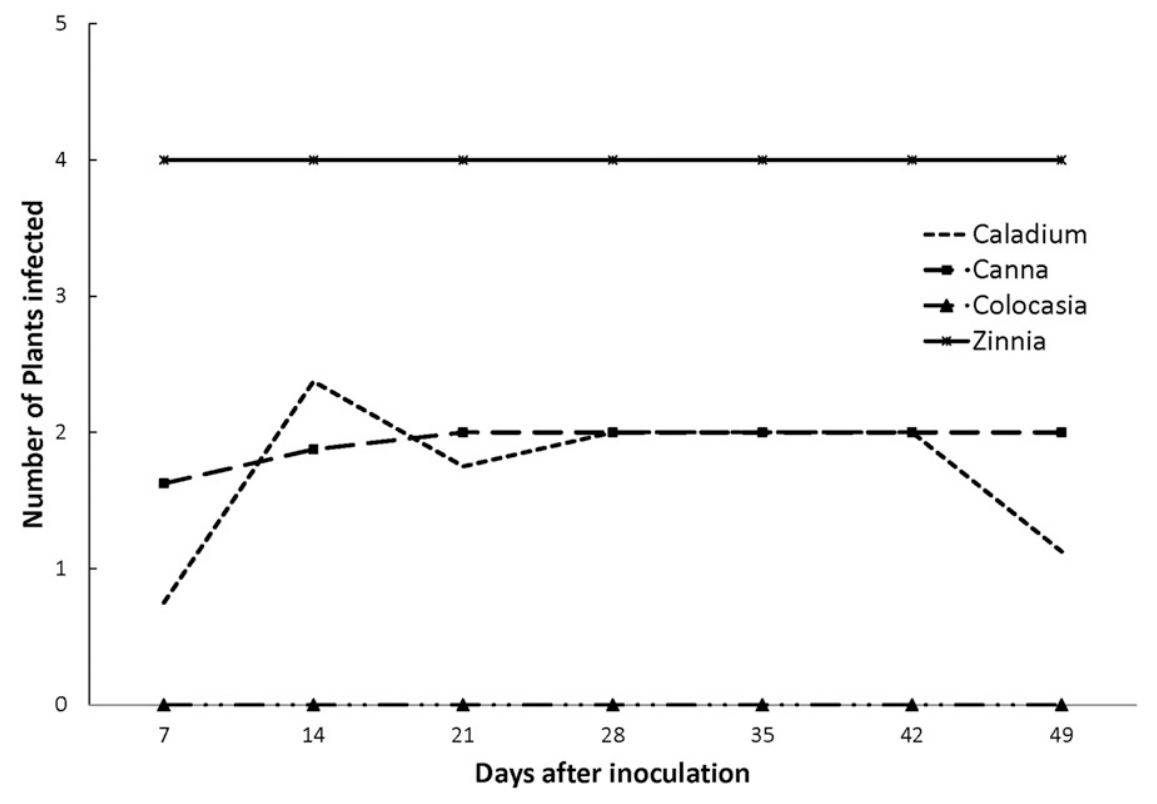

Fig. 1. Disease incidence, measured as percent of plants infected by Sclerotinia sclerotiorum over time based on signs and symptoms; combined data from 2012 and 2013 field trials.

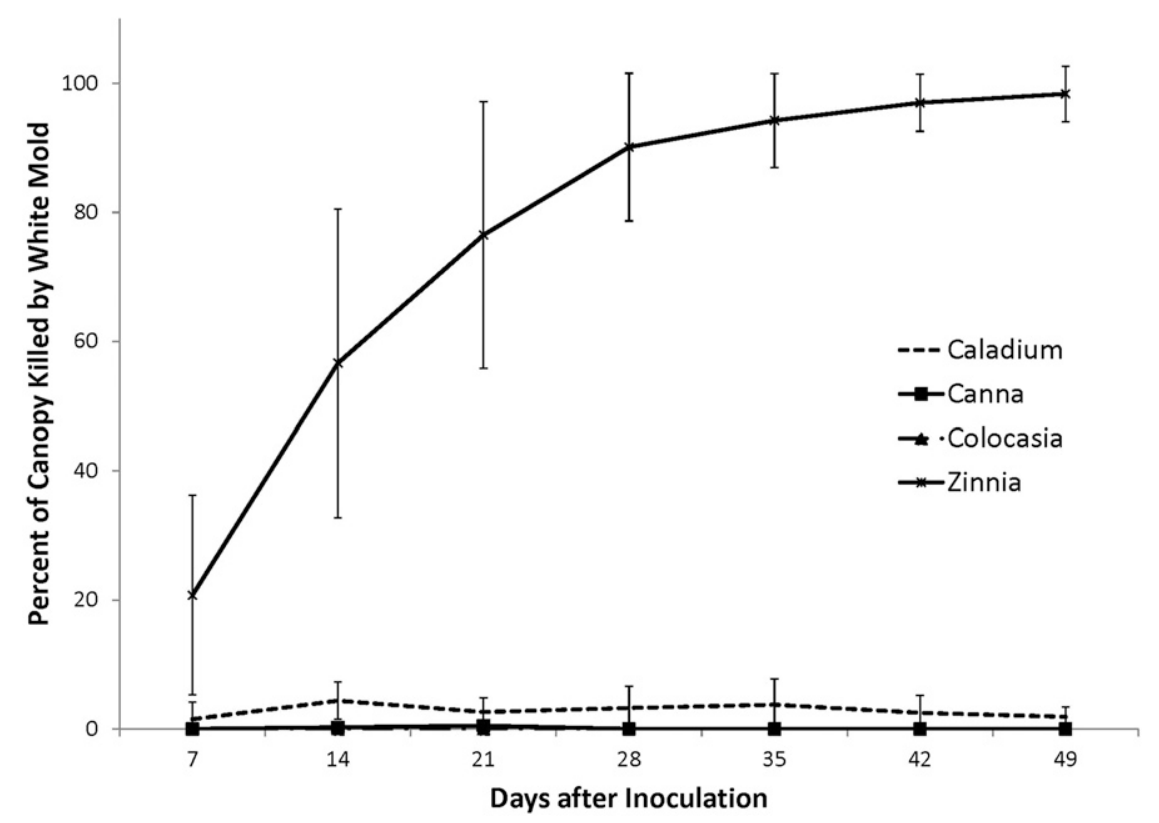

Fig. 2. Disease severity, measured as percentage of canopy killed by Sclerotinia sclerotiorum over time; error bars represent standard deviation; combined data from 2012 and 2013 field trials.

for elephant ear was $0 \%$ throughout both years (Fig. 1). Canopy death in caladium never exceeded $11 \%$ and no canopy death was recorded for canna or elephant ear in either year (Fig. 2). The AUDPC for incidence and severity was highest for zinnia followed by caladium, canna, and elephant ear (Table 1).

\section{Studies in controlled environments}

Inoculation of foliage. Inoculated caladium cultivars had significantly greater disease severity than mock-inoculated controls. 'White Queen' caladium had significantly greater disease severity than all other plants tested. Disease severity of elephant ear and canna was not significantly different from mock-inoculated controls (Table 2).

Inoculated caladium petioles developed soft rot, resulting in wilt of one to several leaves as early as 7 DAI. Mycelia and sclerotia were commonly observed on infected petioles at 24 DAI. The infection progressed into the tuber on $44 \%$ of 'White Queen' caladium plants and $20 \%$ of 'Fannie Munson' caladium plants. Inoculated canna leaves developed dry brown necrotic lesions averaging $3.3 \mathrm{~cm}$ in length at the site of infection 24 DAI. This lesion resulted in wilt of the inoculated leaf in $8 \%$ of plants. Petiole infection of canna never progressed into the 
Table 1. Combined area under disease progress curve (AUDPC) for incidence and severity of white mold in field-inoculated ornamental tropical plants in 2012 and 2013.

\begin{tabular}{llcr}
\hline Plant & Cultivar & Incidence AUDPC & Severity AUDPC \\
\hline Zinnia elegans $\times$ angustifolia & Profusion White & $170 \mathrm{a}^{\mathrm{z}}$ & $3234.5 \mathrm{a}$ \\
Caladium $\times$ hortulanum & White Queen & $78.4 \mathrm{~b}$ & $129 \mathrm{~b}$ \\
Canna $\times$ generalis & Tropical White & $81.6 \mathrm{~b}$ & $4.75 \mathrm{c}$ \\
Colocasia esculenta & Ruffles & $0 \mathrm{c}$ & $0 \mathrm{c}$ \\
\hline
\end{tabular}

${ }^{\mathrm{z}}$ Measurements within a column with the same letter are not significantly different at $\alpha=0.001$ by Wilcoxon's rank test.

Table 2. Percent foliage wilted or killed at $24 \mathrm{~d}$ after inoculation by Sclerotinia sclerotiorum in a controlled environment.

\begin{tabular}{lllc}
\hline Scientific name & \multicolumn{1}{c}{ Cultivar } & \multicolumn{1}{c}{ Treatment } & Percent leaf death \\
\hline Caladium $\times$ hortulanum & White Queen & S. sclerotiorum & $65.4 \mathrm{a}^{\mathrm{y}}$ \\
Caladium $\times$ hortulanum & Fannie Munson & S. sclerotiorum & $38.9 \mathrm{~b}$ \\
Colocasia esculenta & Ruffles & S. sclerotiorum & $21.1 \mathrm{bc}$ \\
Colocasia esculenta & Ruffles & Mock-inoculated control & $20.7 \mathrm{bc}$ \\
Canna $\times$ generalis & Tropical Yellow & S. sclerotiorum & $1.6 \mathrm{c}$ \\
Canna $\times$ generalis & Tropical White & S. sclerotiorum & $0.9 \mathrm{c}$ \\
Canna $\times$ generalis & Tropical White & Mock-inoculated control & $0.0 \mathrm{c}$ \\
Caladium $\times$ hortulanum & White Queen & Mock-inoculated control & $0.0 \mathrm{c}$ \\
Canna $\times$ generalis & Tropical Yellow & Mock-inoculated control & $0.0 \mathrm{c}$ \\
Caladium $\times$ hortulanum & Fannie Munson & Mock-inoculated control & $0.0 \mathrm{c}$ \\
\hline
\end{tabular}

${ }^{\mathrm{z}}$ Data from inoculation with three different $S$. sclerotiorum isolates were combined after analysis revealed no significant difference in disease severity between isolates and no interaction between plant entry and isolate.

${ }^{\mathrm{y}}$ Measurements with the same letter are not significantly different at $\alpha=0.05$ by Tukey's honestly significant difference test.

Table 3. Percentage of below ground storage organ rotted at $10 \mathrm{DAI}$ after wound inoculation with $S$. sclerotiorum isolate ORN010.

\begin{tabular}{lllcc}
\hline Scientific name & \multicolumn{1}{c}{ Cultivar } & Storage organ & $\begin{array}{c}\text { Percent plants } \\
\text { infected }\end{array}$ & $\begin{array}{c}\text { Percent storage organ } \\
\text { tissue rotted }\end{array}$ \\
\hline Canna $\times$ generalis & Tropical White & Rhizome & $0 \mathrm{~b}^{\mathrm{z}}$ & $0 \mathrm{~b}$ \\
Colocasia esculenta & Ruffles & Corm & $0 \mathrm{~b}$ & $0 \mathrm{~b}$ \\
Caladium $\times$ hortulanum & White Queen & Tuber & $25 \mathrm{~b}$ & $11 \mathrm{~b}$ \\
Daucus carota subsp. sativus & unknown & Taproot & $100 \mathrm{a}$ & $48 \mathrm{a}$ \\
\hline
\end{tabular}

${ }^{\mathrm{z}}$ Measurements with the same letter are not significantly different at $\alpha=0.001$ by Wilcoxon's rank test.

main stem or rhizome. The outermost leaf of both inoculated and mock-inoculated elephant ear plants turned yellow to brown and wilted 24 DAI. Sclerotinia sclerotiorum was isolated from inoculated leaves but it was unclear if infection occurred before natural leaf senescence. Infection did not progress into elephant ear corms.

Infection of canna flowers. Canna flowers became infected when directly inoculated. Discolored petals and mycelia were observed on petals as early as 6 DAI. Within the inoculated inflorescence, an average of $25 \%$ of the flowers were infected 6 DAI and $68 \%$ of flowers were infected 19 DAI. By 28 DAI, all flowers had naturally senesced. Flower stalk infection occurred in $100 \%$ of plants, averaging $6.5 \mathrm{~cm}$ in length, or $48 \%$ of the length of the flower stalk. Infected flower stalks developed brown elongate lesion progressing upward and downward from the infected flower. Infections initiated in the inflorescence never girdled the flower stalk, progressed to the main stem, or resulted in infection of leaves or secondary inflorescences.

Infection of elephant ear petioles. At 28 DAI, all young newly expanded elephant ear leaves remained green and turgid, and all old leaves from the outer whorl turned yellow and wilted regardless of inoculation with field or controlled environments. This is also the first report of susceptibility of caladium cultivars to white mold. The petioles, leaves, and tubers of tested cultivars were readily colonized by $S$. sclerotiorum, resulting in soft rot and production of sclerotia. Wilt and death of the canopy and the progression of the infection into tubers makes these cultivars of caladium unsuitable for use in landscape beds infested with $S$. sclerotiorum.

A significant difference in disease severity was observed between the two caladium cultivars in controlled environments, suggesting that there may be varying levels of resistance to $S$. sclerotiorum within cultivars of caladium. The pedigrees of many cultivars of Caladium $\times$ hortulanum are unknown, but most are believed to originate from $C$. bicolor, C. picturatum, C. marmoratum, or C. schomburgkii (Deng et al., 2007). Future studies could be conducted to identify resistance in other caladium cultivars or species.

Canna is the sole genus in the family Cannaceae (Prince, 2011). Modern day cultivars of $C$. $\times$ generalis are complex interspecific hybrids involving: $C$. indica, $C$. glauca, C. iridiflora, and C. warscicizzi (Khoshoo and Mukherjee, 1970). Although this study showed high levels of resistance in Canna to $S$. sclerotiorum, the study was limited to two varieties. Future studies should examine a broader range of varieties to determine if resistance is consistent across multiple varieties. In addition, orchid cannas (C. ×orchiodes), a complex hybrid involving the four previous species in $C$. × generalis and $C$. flaccida (Khoshoo and Mukherjee, 1970) should be tested for susceptibility to $S$. sclerotiorum. It may be possible to determine the source of resistance by testing each parent species for resistance.

The results of this study show that susceptibility is not consistent in all members of the Araceae family. Caladium was highly susceptible to infection, suffering soft rot of leaves, petioles, and corms, whereas elephant ear was highly resistant to infection by $S$. sclerotiorum. The pathogen infected only wounded or senescent tissue and did not result in significant symptoms under any conditions.

The Araceae includes a wide variety of ornamental plants for indoor and garden use, in addition to several important food crops. Within the Araceae, plants in two other genera are known to be susceptible to $S$. sclerotiorum: Philodendron spp. and Epipremnum aureum (Boland and Hall, 1994). Cabrera et al. (2008) proposed eight subfamilies of Araceae and Cusimano et al. (2011) proposed 44 clades of Araceae. Philodendron, Caladium, and Colocasia are in subfamily Aroideae. Epipremnum is in subfamily Monsteroideae. The four Aroid genera found to be susceptible to white mold are in different clades. This indicates that susceptible plants can be found in multiple subfamilies and that both resistant and susceptible plants occur in subfamily Aroideae. Future studies should examine multiple genera from the same clade to 
determine if resistance is specific to clade or genus.

This study demonstrates that elephant ear and canna are good candidates for planting in landscape beds infested with S. sclerotiorum. Canna varieties come in a wide range of heights, foliage, and flower colors, allowing them to be used in diverse landscape roles. Because of their large size, elephant ear plants could be used where space allows. Because the pathogen was able to colonize tissue of both elephant ear and canna, the use of these plants in infested landscape beds should include the removal of plants from the garden bed at the end of the growing season to minimize overwintering of the pathogen in infected plant debris.

\section{Literature Cited}

Abawi, G.S. and R.G. Grogan. 1979. Epidemiology of diseases caused by Sclerotinia species. Phytopathology 69:899-904.

Boland, G.J. and R. Hall. 1994. Index of plant hosts of Sclerotinia sclerotiorum. Can. J. Plant Pathol. 16:93-108.

Bolton, M.D., B.P.H.J. Thomma, and B.D. Nelson. 2006. Sclerotinia sclerotiorum (Lib.) de Bary: Biology and molecular traits of a cosmopolitan pathogen. Mol. Plant Pathol. 7:1-16.

Cabrera, L.I., G.A. Salazar, M.W. Chase, S.J. Mayo, J. Bogner, and P. Dávila. 2008. Phylogenetic relationships of aroids and duckweeds (Araceae) inferred from coding and noncoding plastid DNA. Amer. J. Bot. 95:1153-1165.

Chang, K.F., R.J. Howard, R.G. Gaudiel, and S.F. Hwang. 1997. First report of Sclerotinia sclerotiorum on coneflower. Plant Dis. 81:1093.
Cusimano, N., J. Bogner, S.J. Mayo, P.C. Boyce, S.Y. Wong, M. Hesse, W.L.A. Hetterscheid, R.C. Keating, and J.C. French. 2011. Relationships within the Araceae: Comparison of morphological patterns with molecular phylogenies. Amer. J. Bot. 98:654-668.

Daughtrey, M.L., R.L. Wick, and J.L. Peterson. 1995. Compendium of flowering potted plant diseases. APS Press, St. Paul, MN.

Deng, Z., F. Goktepe, B.K. Harbaugh, and J. Hu. 2007. Assessment of genetic diversity and relationships among caladium cultivars and species using molecular markers. J. Amer. Soc. Hort. Sci. 132:219-229.

Farr, D.F. and A.Y. Rossman. 2017. Fungal databases, U.S. National Fungus Collections, ARS, USDA. 27 Apr. 2017. <https://nt.ar-grin.gov/ fungaldatabases/ $>$.

Garibaldi, A., A. Minuto, and M.L. Gullino. 2001. First report of Sclerotinia sclerotiorum on Calendula officinalis in Italy. Plant Dis. 85:446.

Garibaldi, A., A. Minuto, and M.L. Gullino. 2008a. First report of Sclerotinia sclerotiorum on Calceolaria integrifolia in Italy. Plant Dis. 92:1133.

Garibaldi, A., P. Pensa, and M.L. Gullino. 2008b. First report of Sclerotinia sclerotiorum on Argyranthemum frutescens in Italy. Plant Dis. 92:1250.

Garibaldi, A., P. Pensa, A. Minuto, and M.L. Gullino. 2008c. First report of Sclerotinia sclerotiorum on Lantana camara in Italy. Plant Dis. 92:1369.

Germplasm Resources Information Network. 2017. National plant germplasm system. ARS. USDA. 27 Apr. 2017. <www.ars-grin.gov>.

Gleason, M.L., M.L. Daughtrey, A.R. Chase, G.W. Moorman, and D.S. Mueller. 2009. Diseases of herbaceous perennials. APS Press, St. Paul, MN.

Grabowski, M.A. and D.K. Malvick. 2015. Evaluation of annual bedding plants for resistance to white mold. HortScience 50:259-262.

Gulya, T.J., R.W. Gesch, C.A. Bradley, L.E. del Rio, and B.L. Johnson. 2006. First report of Sclerotinia sclerotiorum infection on Cuphea. Plant Dis. 90:1554.

Horst, R.K. 2001. Westcott's plant disease handbook, 6th ed. Kluwer Academic Publishers, Norwell, MA

Iversen, R.R. 1999. The exotic garden: Designing with tropical plants in any climate. Taunton Press, Newtown, CT.

Khoshoo, T.N. and I. Mukherjee. 1970. Geneticevolutionary studies on cultivated cannas. Theor. Appl. Genet. 40:204-217.

Koike, S.T. 2007. Vegetable diseases: A color handbook, plant protection handbooks series. Academic Press, Burlington, MA.

Madden, L., G. Hughes, and F. van den Bosch. 2007. The study of plant disease epidemics. APS Press, St. Paul, MN.

Prince, L.M. 2011. Phylogenetic relationships and species delimitation in Canna (Cannaceae), p. 307-331. In: O. Seberg, G. Petersen, A.S. Barfod, and J. Davis (eds.). Diversity, phylogeny, and evolution in the monocotyledons. Aarhus University Press, Aarhus, Denmark.

Quero-Garcia, J., A. Ivancic, and V. Lebot. 2010. Taro and cocoyam, p. 149-172. In: J.E. Bradshaw (ed.). Root and tuber crops, handbook of plant breeding. Springer, New York, NY.

Strauss, J. and H.R. Dillard. 2009. First report of Sclerotinia stem rot caused by Sclerotinia sclerotiorum on Hibiscus trionum in New York. Plant Dis. 93:673. 